[ FELICIA ASSMAR MAIA ]

Advogada e jornalista. Especialista em Cultura de Moda pela Universidade Anhembi Morumbi, em São Paulo. É coordenadora do Curso de Design de Moda da Faculdade Estácio de Sá/Faculdade do Pará e docente da Universidade da Amazônia.

E-mail: feliciaassmarmaia@hotmail.com

\title{
Fibras da Amazônia: a moda artesanal como indicação geográfica
}
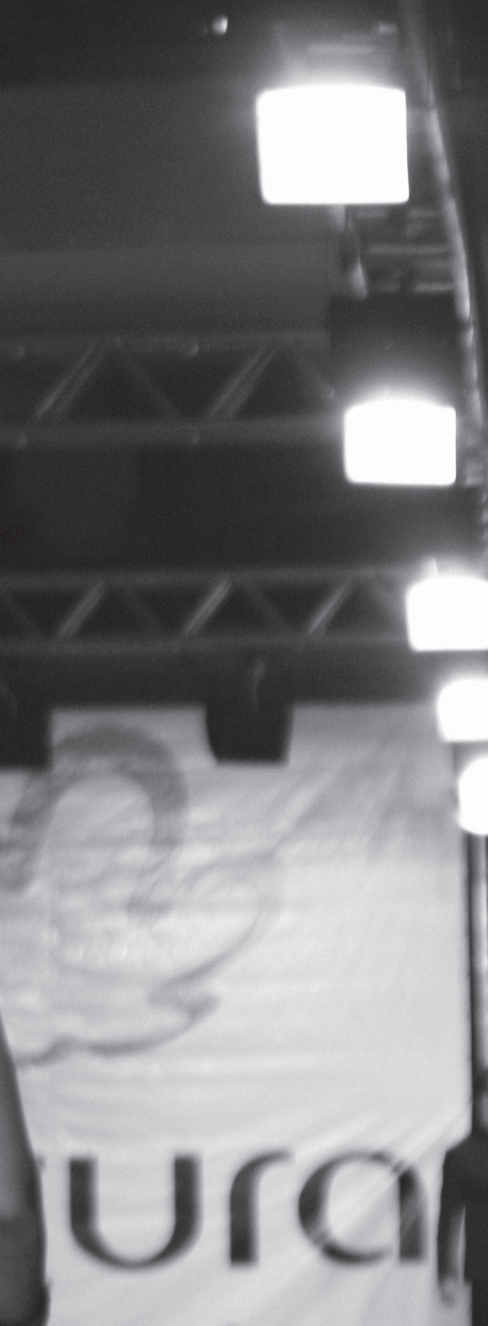
tar bem 
Num momento em que a produção de moda no Brasil passa a representar parcela significativa do Produto Interno Bruto Nacional, despontam movimentos com vistas a engajar nesse mercado promissor produtos com identidade regional que representem um diferencial no atual cenário de globalização.

A Amazônia é um lugar sui generis que vive em constante verão sob o sol escaldante do Equador e, justamente por causa de tais condições geográficas, tem frutos, sementes e fibras muito peculiares, que inspiram a criação de moda com forte identidade local. A região, no entanto, debate-se em meio à tendência mundial de minimização das diversidades culturais e, sem a intenção de frear o curso da história ou "remar contra a maré", embarca nesse movimento de modernidade, não sem levar na bagagem seu regionalismo e o potencial criativo de seu povo.

Assim, a moda desenvolvida na Amazônia impõe-se como importante foco de pesquisa na medida em que recursos naturais, como, por exemplo, as fibras, passam a ser usados, exportados e conhecidos no mundo todo. Dessa forma, faz-se necessário um trabalho de preservação da origem, caso contrário, esses recursos correm o risco de perder sua identidade geográfica.

Dentre as matérias-primas mais utilizadas na criação de moda estão as chamadas "fibras de vestir", destacando-se a juta e o tururi, hoje amplamente empregadas na confecção de roupas e acessórios.

A juta, cujo nome científico é corchorus capsularis, é uma planta têxtil pertencente à família das tiláceas, que exige solo fértil e bem drenado, assim como clima quente e úmido. 0 principal componente dessa fibra têxtil é a celulose. As melhores qualidades de juta são as que apresentam robustez das fibras e a cor branca e brilhante do talo.

Afeita a climas quentes e úmidos, a juta, que sempre foi cultivada em grande escala na Índia e em Bangladesh (antigo Paquistão Oriental), adaptou-se de maneira extraordinária à região amazônica, principalmente em razão da presença da malva, fibra nativa do Estado do Pará, e posteriormente foi cultivada no Estado do Amazonas. A esse fator natural aliou-se a relativa facilidade de exploração regional da planta e 0 sucesso da comercialização das fibras no mercado nacional.

Trazida para a Amazônia nos primeiros anos da imigração japonesa no início do século XX, a variedade conhecida atualmente como juta branca, juta verde ou juta Oyama - descoberta, em 1934, pelo colono japonês Ryoto Oyama - passou a ser cultivada, pois tinha características idênticas às da juta indiana, tornando-se a melhor espécie aclimatada na região. Desde então, a produção alcança resultados satisfatórios, tendo como razões fundamentais o baixo custo de produção agrícola, a proximidade do vale do Amazonas dos principais centros consumidores e a abundância do tipo apropriado de água, extremamente necessária para plantas cujos troncos contêm fibras.

Inicialmente, as fibras de juta, chamadas comercialmente de "fibras moles", foram utilizadas na confecção de telas e tecidos de aniagem, serrapilhas, cordas, barbantes e tapetes, e durante muito tempo essa produção teve apenas uma função utilitária, servindo para estocagem de produtos, como diversos tipos de grãos. Com 0 desenvolvimento de técnicas artesanais e a produção de artigos para turistas, a juta foi usada para confeccionar sacolas de praia.

0 desejo de criar moda com identidade regional levou estilistas e artesãos a investir na busca de novas matérias-primas, como a juta, para a produção de roupas, acessórios e até mesmo no prêt-à-porter de luxo - em vestidos de noiva, inclusive, tem sido frequente sua utilização.

A fibra de tururi - usada primeiramente pelos índios em telhados de casas graças à sua durabilidade, impermeabilidade e resistência - é utilizada na confecção de acessórios de moda, tais como bolsas e colares, e mais recentemente ganhou o status de "tecido nobre".

Essa fibra é extraída de uma palmeira chamada de ubuçu (manicaria sacifera), da familia das palmáceas, abundante nas margens das várzeas e ilhas da Amazônia, principalmente nos Estados do Amazonas, Pará e Amapá. 0 ubuçu, que cresce em floresta fechada, mede de 3 a 6 metros de altura, tem folhas grandes e quase inteiras, assemelhando-se às da bananeira. 0 cacho que pende da palmeira é protegido por um invólucro semelhante a um saco de material fibroso e resistente chamado de tururi. É esse material, recolhido após cair no chão ou retirado pelo caboclo com a ajuda da peconha' ${ }^{1}$ que, por apresentar características de flexibilidade e resistência, transformou-se em tecido de larga utilização na produção de moda. 
0 processo de tratamento da fibra é simples e dispensa produtos químicos. Após a retirada da árvore, a fibra é submetida a secagem, lavagem e amaciamento e, posteriormente, passa por um processo de mercerização - acabamento que faz aumentar o brilho da fibra, tornando-a mais encorpada e resistente -, ficando de molho para ser novamente enxaguada e seca, e só então adquire condições para o uso.

A criatividade e a habilidade manual do povo da Amazônia, somadas à capacitação para atender as exigências do mercado, têm conduzido à melhor utilização da fibra e sua valorização no mercado da moda.

Importante ressaltar que grifes consagradas no mundo todo empenham-se na proteção de seus ativos intelectuais, as criações de moda. Os designs ou desenhos industriais necessitam de proteção específica, pois só assim seus titulares poderão coibir terceiros de explorar, de modo inadequado e não autorizado, os aspectos originais e estéticos de seus trabalhos. Tendo em vista que a marca (e logotipo) pode agregar valor ao produto, seu registro torna-se fundamental para presenvar sua integridade e defendê-la da concorrência.

Além do registro da marca, as legislações contemporâneas não só trazem dispositivos de defesa dos direitos do criador ou do produto, mas também de valorização e mesmo defesa de determinadas regiões. São as chamadas Indicações Geográficas, que visam distinguir a origem de um produto ou serviço em virtude da qualidade e/ou excelência de sua manufatura ou em virtude da fama de uma área geográfica pela comercialização ou obtenção de um determinado produto.

No Brasil, o registro de Indicações Geográficas foi uma das inovações introduzidas pela Lei 9.279 de 14 de maio de 1996, conhecida como Lei da Propriedade Industrial. Trata-se de um registro implementado pelo Instituto Nacional da Propriedade Industrial (INPI), por meio do qual o maior beneficiário é o local de produção do bem ou serviço, garantindo ao lugar benefícios semelhantes aos da identidade de marca.

De acordo com a Lei, as Indicações Geográficas podem ser classificadas em indicação de procedência e denominação de origem. A indicação de procedência é o nome geográfico de um país, cidade, região ou localidade de um território que se tornou conhecido como centro de produção, fabricação ou extração de determinado produto ou prestação de determinado serviço, como a cidade de Paris, conhecida pelos perfumes, e a de Franca, em São Paulo, pelos calçados. A denominação de origem é o nome geográfico do país, cidade, região ou localidade de seu território, que designa produto ou serviço cujas qualidades ou características são inerentes ao meio geográfico - fatores naturais e humanos - como Minas Gerais para queijos e Bento Gonçalves, no Rio Grande do Sul, para vinhos.

A região amazônica deve trabalhar para obter o registro para a moda artesanal feita com as fibras de juta e tururi. É bem verdade que se trata de um registro de caráter facultativo, mas sua obtenção atuaria como um elemento informativo da origem do produto, garantindo-lhe maior segurança, inclusive contra cópias ou apropriações indevidas.

0 pedido de reconhecimento de Indicação Geográfica, que pode ser feito por sindicatos, associações, institutos ou pessoa jurídica de representatividade coletiva com legítimo interesse, estabelecida no respectivo território, é apresentado em formulário próprio ao INPI. Nesse requerimento devem ser fornecidas informações sobre a área geográfica, sua delimitação, descrição do produto ou serviço; é necessário apresentar ainda o comprovante do recolhimento da retribuição devida, da procuração e das etiquetas, se for o caso.

Após serem interpostos no INPI, os pedidos serão decididos em primeira instância por uma comissão julgadora composta por servidores do próprio Instituto. Em instância superior, por uma Comissão Mista, integrada por um representante de cada um dos seguintes Ministérios: Indústria e Comércio, Turismo, Agricultura, um representante do órgão ou entidade com o qual estiverem relacionados os pedidos e três servidores do INPI. Uma vez deferido, o registro permanece em vigor enquanto o produto ou serviço apresentar suas características específicas. 